\title{
Research on the Difference of Regional Financial Agglomeration in Shandong Province of China
}

\author{
Ruibo Liu \\ School of finance, Yanshan School \\ Shandong University of Finance and Economics \\ Jinan, China \\ sdcdlrb5276@163.com
}

\author{
Xi Zhang* \\ School of finance \\ Shandong University of Finance and Economics \\ Jinan, China \\ 392551536@qq.com
}

\begin{abstract}
With the continuous deepening of the financial system reform, the degree of financial agglomeration has become an important symbol of economic development and has an irreplaceable impact on economic growth. Therefore, this paper selects the data of Shandong Province from 2004 to 2016, and calculates the financial concentration degree of "two circles and four areas" in Shandong Province by means of Financial Entropy Index and Theil Index, The conclusion is that the degree of financial agglomeration in the Jinan metropolitan area and Qingdao metropolitan area is high, and the financial entropy coefficient is greater than 1 in the statistical year. Subsequently, through analysis, we found that the average level of the intraregional differences was $\mathbf{0 . 1 3 5}$, and the average level of interregional differences was $\mathbf{0 . 0 8 1 9}$. It was concluded that the difference in financial agglomeration within the region had a great influence on the total variance.
\end{abstract}

Keywords-financial agglomeration; financial entropy; Gini coefficient; Theil index

\section{INTRODUCTION}

In recent years, with the further development of the global economy, financial resources, financial activities, and financial institutions have begun to gather in a few important financial centers and the degree has been continuously deepened. The impact of financial agglomeration on regional economic development has gradually emerged. Shandong's economy is large but not strong, and its development is fast and uneven. In order to fully connect with the national regional development strategy, support the construction of national central cities in Jinan and Qingdao, and guide the effective development of Yanwei, Dongbin, Jizhaohe and Linji metropolitan areas, the Shandong provincial government divided the Shandong Peninsula into "two circles and four areas".In these six regions, the degree of financial agglomeration in the Qingdao metropolitan area and the Jinan metropolitan area is relatively high, while the financial development in other areas is relatively low. Therefore, studying the "two-ring four-area" regional financial agglomeration phenomenon and the differences in regional economic development to find out the form of regional economic development will provide a good guideline for the future development of the financial industry in Shandong Province.

For the study of the differences in regional economic development, scholars usually use the Gini coefficient and the

This research was financially supported by the Shandong Provincial Institute of Science and Technology Project J17RA225.
Theil index to carry out the study. The following will describe the representative literature.

Tian Zhaoping [1] measured the regional economy of Jiangsu Province from 2000 to 2008 by using the Gini coefficient and the Theil index, and believed that the expansion of the regional economic differences in Jiangsu Province mainly comes from the development differences of the second industry. Jiang Xia and Guo Keyan [2] used the financial entropy coefficient formula to calculate the relevant data of Hubei Province from 1996 to 2014, and obtained the extent of financial agglomeration in Hubei Province. Wu Jinhong and Huang Xiujuan [3] analyzed the absolute differences, relative differences, and Taylor coefficient values of the three major regional economies in Jiangsu Province from 2000 to 2010, and concluded that the regional economic differences in Jiangsu province have been expanding year by year but the pace has gradually slowed down. Shen Li [4] took the 19782009 data of 31 provinces in China as a sample, and used the Dagum Gini Coefficient method to measure the regional disparities in China's financial development by using the financial correlation ratio as a measure. Through research, it is found that during the period of sample review, the overall gap in China's financial development shows an expanding trend, and the gap between regions is the main source of the overall gap. On this basis, it proposes measures to promote the coordinated development of finance in different regions. Yu Lu and Jiang Yuantao [5] innovatively compared the three major metropolitan areas with the overall national level to study the spatial-temporal evolution of regional economic disparities. After they learned that the more imbalanced regional economic development is, the greater the interdependence of economic development among individuals within the region will be. Zheng Changde [6] used the method of Theil Index decomposition to study the regional differences in China's financial development, and the process of marketization, government intervention, legal environment, and macroeconomic conditions were all factors that caused this difference. Yu Chengxue [7] innovatively used the Theil Index multi-index measurement method and designed five measurement indexes to analyze the differences in regional economic development in China. In addition, Zhao Wei and Ma Ruiyong [8] also used the measure of the Theil Index to study the differences in financial growth in the Chinese region. 
After sorting through the literature, most scholars used the Gini coefficient and the Theil index to measure regional disparities when studying regional economic development differences. Therefore, first of all, this paper calculates the degree of financial agglomeration in the six regions of Shandong Province by calculating the financial entropy coefficient of "two circles and four regions" in Shandong Province. Secondly, using the Gini coefficient and the Theil index to decompose the financial agglomeration differences. Finally, draw relevant conclusions.

\section{ThE DifFERENCE ANALYSIS OF FinANCIAL Agglomeration in SHANDONg Province}

\section{A. The Current Situation of Financial Agglomeration in Shandong Province}

In order to clearly understand the current situation of financial aggregation in Shandong Province, this paper uses the improved financial entropy indicators to statistically measure the concentration of financial industry in Shandong Province.

\section{1) Standard Location Entropy}

Location entropy refers to the ratio of the output value of a specific industry in a region to the total output value of the region and the ratio of the output value of the industry in the country to the total output value of the country. It can measure the difference between the production structure of the region and the national average and is an important measure of the degree of industrial aggregation. The formula for calculating the degree of agglomeration of a region's industries is as follows.

$$
\beta_{i j}=\frac{Q_{i j} / Q_{j}}{Q_{i} / Q}
$$

$Q_{\mathrm{ij}}$ is the output value of the industry $\mathrm{i}$ in the $\mathrm{j}$ area, $Q_{j}$ is the industrial output of the $\mathrm{j}$ area, $Q_{i}$ is the national output value of the industry $i$, and $Q$ is the total industrial output value of the country. If $\beta_{i j}$ is greater than 1 , it indicates that the industry clustered in the region exceeds the national level, and the industry may have a clustering phenomenon; if $\beta_{i j}$ is less than 1 , it indicates that the cluster level of the studied industry in the region is lower than the national level.

2) Improved Location Entropy - Financial Entropy Coefficient

Because the standard location entropy coefficient emphasizes the comparison between the economic development of an industry responding to a region in the region and the development of an industry in the country, the relative relationship is more important. This paper hopes to more intuitively experience financial agglomeration from a geographic perspective. Therefore, this paper selects the relative geographical density of financial agglomeration as an indicator to measure the level of financial agglomeration, and combines the actual situation in Shandong Province with Shandong Province's financial market as indirect financing. Therefore, the regional deposit and loan balance was chosen as a variable to measure the level of financial development, and the regional entropy was improved to financial entropy as follows:

$$
\beta_{i}=\frac{D_{i} / S_{i}}{D / S}
$$

$D_{i}$ indicates deposit and loan balance in $\mathrm{i}$ area, $S_{i}$ indicates land area in $\mathrm{i}, D$ indicates the deposit and loan balance of the whole province, $S$ shows the land area of the whole province.

\section{B. Measurement Method of Financial Agglomeration Diversity}

\section{1) Gini Coefficient Method}

The Gini coefficient is an indicator of the level of fairness of income distribution defined by the American economist Albert Hirschmann in 1943 based on the Lawrence curve. The value of the Gini coefficient is between 0 and 1 , which is an important analytical indicator used to comprehensively examine the differences in internal income distribution among residents. Its calculation formula is:

$$
G I N I=\frac{-(n+1)}{n}+\frac{2}{n^{2} \mu_{y}} \sum_{i=1}^{n} i y_{i}
$$

Among them, $n$ represents the number of samples, $y_{i}$ indicates the level of financial accumulation in the i-th region after the financial accumulation level is ranked from low to high, and $\mu_{y}$ indicates the average level of financial agglomeration. This paper uses the previously calculated regional financial entropy coefficients to reflect the regional Financial agglomeration level.

\section{2) Theil Index Method}

In order to accurately reflect the regional financial growth between the "two circles and four areas" and the differences in the financial growth within the six regions, this paper decided to adopt the Theil Index method. It can better meet our requirements by describing the differences between regions, such as the Gini Coefficient. The Theil index method is used to analyze the differences in regional financial growth in Shandong Province. According to the definition and formula of the Theil index, there are:

Tyre 0th order index:

$$
T_{0}=\frac{1}{N} \sum_{i \in N} \ln \frac{\mu}{y_{i}}
$$

Theil index:

$$
T_{1}=\frac{1}{N} \sum_{i \in N} \frac{y_{i}}{\mu} \ln \frac{y_{i}}{\mu}
$$

Among them, $N$ indicates the number of study areas, $\mu$ is the average financial aggregation level in the province, that is, the average financial entropy in the province, $y_{i}$ is the financial 
entropy of the i-th area. $T_{0}$ is the Tier 0 index, $T_{1}$ is the Theil index.

In order to better observe the differences in the level of financial agglomeration in the six regions of Shandong Province, the difference is due to intra-group differences or the difference between groups. The Theil Index is broken down as

$$
\begin{aligned}
& T 0(y)=\frac{1}{n} \sum_{k=1}^{m} \sum_{i \in N_{k}} \ln \frac{\mu}{y_{i}} \\
& \text { follows: } \quad=\sum_{k=1}^{m} \frac{n_{k}}{n} * \frac{1}{n_{k}} \sum_{i \in N_{k}} \ln \frac{\mu_{k}}{y_{i}}+\frac{1}{n} \sum_{k=1}^{m} \sum_{i \in N_{k}} \ln \frac{\mu}{\mu_{k}} \\
& =W+B \\
& T 1(y)=\frac{1}{n} \sum_{k=1}^{m} \sum_{i \in N_{k}} \frac{y_{i}}{\mu_{y}} \\
& =\sum_{k=1}^{m} \frac{n_{k}}{n} * \frac{\mu_{k}}{\mu_{y}} * \frac{1}{n_{k}} \sum_{i \in N_{k}} \frac{y_{i}}{\mu_{k}} \ln \frac{y_{i}}{\mu_{k}}+\frac{1}{n} \sum_{k=1}^{m} \sum_{i \in N_{k}} \frac{\mu_{k}}{\mu_{y}} \ln \frac{\mu_{k}}{\mu_{y}} \\
& =\sum_{k=1}^{m} v_{k} \frac{\mu_{k}}{\mu_{y}} T\left(y^{k}\right)+\sum_{k=1}^{m} v_{k} \frac{\mu_{k}}{\mu_{y}} \ln \frac{\mu_{k}}{\mu_{y}} \\
& =W+B
\end{aligned}
$$

$$
\text { suppose } f(k)=v_{k} \frac{\mu_{k}}{\mu_{y}}
$$

In the above two formulae, $\mathrm{n}$ represents the number of samples, $m$ represents the number of groups into which $n$ is divided, $\mu_{k}$ represents the average value of financial agglomeration level, and $f(k)$ is the ratio of the financial concentration level of the $k$-th group to the total financial agglomeration level. $\mathrm{W}$ is the difference between the groups, $\mathrm{B}$ is the difference within the group, and the Theil index is decomposable. Therefore: $\mathrm{T}=\mathrm{W}+\mathrm{B}$, that is, the total difference is equal to the sum of the difference between the groups and the difference within the group. In order to study the influence of the gap between the groups and the gap within the group on the overall Theil Index, we define the contribution rate between groups and the contribution rate within the group: the contribution rate between groups = the gap between groups $/ \mathrm{T}$, the contribution rate within the group = the gap within the group / T.

\section{Comparative Analysis of the Results of}

\section{FinANCIAL Agglomeration DegReE AND ITS DifFERENCES}

According to the document "Development Plan of Shandong Peninsular City Cluster (2016-2030)" issued by the People's Government of Shandong Province, the overall pattern of "two-circle, four-area, network development" based on Jinan metropolitan area and Qingdao metropolitan area is proposed. The Shandong Province is divided into six regions .The data comes from the Statistical Yearbook of Shandong Province and the Statistical Communique of the local cities.

After data processing, the 2004-2016 financial entropy data of the "two circles and four areas" of the province were plotted and graphed, as shown in Fig. 1.

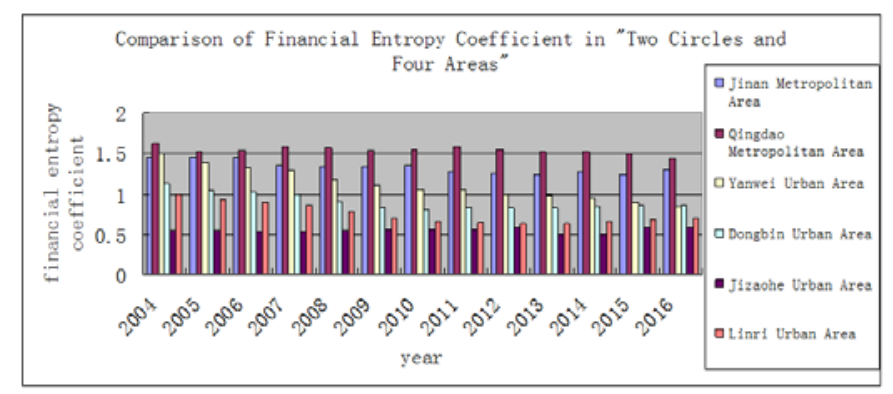

Fig. 1. Comparison of Financial Entropy Coefficient in "Two circles and four areas”

From the above chart, we can clearly see the degree of financial agglomeration in Shandong Province's "two circles and four areas." From a horizontal perspective, the financial development of "two circles and four areas" is quite different. Among them, Jinan metropolitan area and Qingdao metropolitan area have a higher level of financial agglomeration. Their financial entropy coefficient is greater than 1 in the statistical year, which shows that the Jinan metropolitan area The Qingdao metropolitan area is in an absolutely dominant financial agglomeration area; the Yanwei urban area has a financial entropy coefficient greater than 1 between 2004 and 2011, which indicates that the Yanwei urban area has a higher degree of financial agglomeration in this time period; the degree of financial agglomeration in other urban areas is not good. From a longitudinal perspective, in the statistical year, the financial entropy coefficient of each region has risen or declined, and the overall performance is the process of falling first and then rising.

In summary, in the "two circles and four areas", the higher levels of financial agglomeration in Shandong Province are the Jinan metropolitan area and the Qingdao metropolitan area. Although there are also well-developed financial areas such as the Yanwei urban area, the overall level is far behind the Jinan metropolitan area and the Qingdao metropolitan area.

Using the Gini coefficient and the Theil index to calculate the level of financial agglomeration in the six regions of "two circles and four areas" in Shandong Province from 2004 to 2016, the following table shows:

TABLE I. DIFFERENCES IN LEVELS OF FINANCIAL AGGLOMERATION BETWEEN TWO CIRCLES AND FOUR AREAS IN SHANDONG PROVINCE

\begin{tabular}{|c|c|c|}
\hline Year & GINI & T1 \\
\hline 2004 & 0.206220987 & 0.146176543 \\
\hline 2005 & 0.198681124 & 0.142603644 \\
\hline 2006 & 0.202914708 & 0.143568738 \\
\hline 2007 & 0.201633591 & 0.143249225 \\
\hline
\end{tabular}




\begin{tabular}{|l|c|c|}
\hline \multicolumn{2}{|c|}{ Cont. to TABLE I } \\
\hline 2008 & 0.201053233 & 0.140853135 \\
\hline 2009 & 0.204178368 & 0.140744091 \\
\hline 2010 & 0.205216438 & 0.139719195 \\
\hline 2011 & 0.203139087 & 0.138918472 \\
\hline 2012 & 0.19770928 & 0.135768227 \\
\hline 2013 & 0.218210401 & 0.145870694 \\
\hline 2014 & 0.213068746 & 0.145354503 \\
\hline 2015 & 0.1876596 & 0.135025718 \\
\hline 2016 & 0.18843386 & 0.135963985 \\
\hline
\end{tabular}

By observing the data in the table, in general, the Gini coefficient of the financial agglomeration level in the six regions of Shandong Province during 2004-2016 fluctuates around 0.2 , and the fluctuation trend is generally stable, and the fluctuation range is relative in 2011-2015. Larger. In order to see more clearly the changes in the Gini Index and the Theil Index, the stacked line chart is shown as follows:

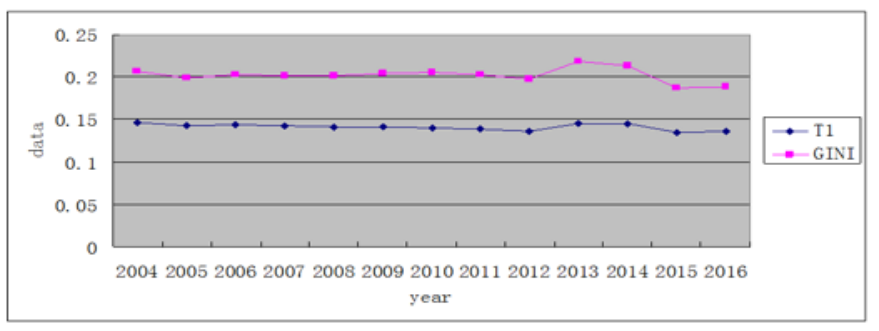

Fig. 2. The Comparison of Two Index
It can be seen that the changes of the two indices are generally consistent. The change from 2004 to 2012 is relatively stable, the Theil index fluctuates within the range of $0.1-0.15$, and the Gini coefficient fluctuates around 0.2 , and is presented between 2012 and 2015. After the rising trend, it dropped again. On the whole, the differences in financial agglomeration levels in the six regions of Shandong Province were stable before 2012, and they fluctuate greatly between 2012 and 2015. On the whole, the fluctuation rule of financial agglomeration level in the six regions is as follows: After a stable fluctuation, then fluctuating period of three years, last it shows a slight increase in stability.

In order to see the inter-regional differences and intraregional differences in the level of financial agglomeration across the six regions, the data of each year was imported into stata13 for the decomposition of Theil Index. The results obtained are shown in the following table:

TABLE II. COMPARISON OF FINANCIAL AGGLOMERATION DIFFERENCES

\begin{tabular}{|c|c|c|c|c|c|}
\hline Year & $\begin{array}{c}\text { intra-regional } \\
\text { differences }\end{array}$ & $\begin{array}{c}\text { Contribution of } \\
\text { intra-regional } \\
\text { differences }\end{array}$ & $\begin{array}{c}\text { Inter-regional } \\
\text { differences }\end{array}$ & $\begin{array}{c}\text { Contribution of } \\
\text { inter-regional } \\
\text { differences }\end{array}$ & Total differences \\
\hline 2004 & 0.15494 & 0.610336 & 0.09892 & 0.389663 & 0.25386 \\
\hline 2005 & 0.15005 & 0.595649 & 0.10186 & 0.404350 & 0.25191 \\
\hline 2006 & 0.15043 & 0.585718 & 0.10640 & 0.414281 & 0.25683 \\
\hline 2007 & 0.13407 & 0.583115 & 0.09585 & 0.416884 & 0.22992 \\
\hline 2008 & 0.1345 & 0.583185 & 0.09613 & 0.416814 & 0.23063 \\
\hline 2009 & 0.13818 & 0.593429 & 0.09467 & 0.406570 & 0.23285 \\
\hline 2010 & 0.14142 & 0.613030 & 0.08927 & 0.386969 & 0.23069 \\
\hline 2011 & 0.12991 & 0.622174 & 0.07889 & 0.377825 & 0.20880 \\
\hline 2012 & 0.12166 & 0.631344 & 0.07104 & 0.368655 & 0.19270 \\
\hline 2013 & 0.11669 & 0.640731 & 0.06543 & 0.359268 & 0.18212 \\
\hline 2014 & 0.12823 & 0.671185 & 0.06282 & 0.328814 & 0.19105 \\
\hline 2015 & 0.10864 & 0.721429 & 0.04195 & 0.278570 & 0.15059 \\
\hline 2016 & 0.14235 & 0.700575 & 0.06084 & 0.299424 & 0.20319 \\
\hline
\end{tabular}

The decomposition results show that during the statistical period from 2004 to 2016, the average coefficient of intraregional difference coefficient for the six regions of "two circles and four areas" is 0.135 , and the average level of the inter-regional difference coefficient is 0.0819. Through observation, it can be seen that the degree of contribution within the region is significantly higher than the contribution of regional differences, and the degree of contribution is increasing year by year, indicating that the differences between regions dominate.

\section{Conclusions AND SUgGestions}

Based on the relevant literature and empirical analysis, this paper selects relevant data from 2004 to 2016 in Shandong
Province. First, it calculates the level of financial agglomeration in "two circles and four areas" in Shandong Province, and then passing the Gini coefficient and the Theil index to analyze the financial agglomeration differences of six areas. The following conclusions were drawn:

First, the financial entropy coefficient results show that the two regions with higher levels of financial agglomeration in Shandong Province are the Jinan metropolitan area and the Qingdao metropolitan area. In the statistical year, the financial entropy coefficients of the two areas are all greater than 1, indicating that the financial agglomeration of the two areas is strong. The degree is higher and the financial industry is developing better. Although there are also well-developed urban areas such as the Yanwei urban area, the overall level 
lags far behind the Jinan metropolitan area and the Qingdao metropolitan area, and as the year changes, the financial entropy coefficient also fluctuates, but overall, it fell first and then rose again.

Second, by analyzing the level of financial agglomeration within regions and between regions and their differences, the average level of the coefficient of difference within the region is 0.135 , and the average level of the coefficient of difference between regions is 0.0819 . The difference in financial agglomeration within the region had a great influence on the total variance. Therefore, the difference in financial agglomeration level in Shandong Province is more caused by intra-regional differences. The difference in inter-regional financial agglomeration level has less impact on total differences.

The guiding significance of the study will include:

First, we must provide strong financial and policy support for the economic development of the Jinan metropolitan area and the Qingdao metropolitan area, and give priority to its development. We must pay attention to the leading role and demonstration role of the economic development in the Jinan metropolitan area and the Qingdao metropolitan area, and gradually expand its radiation capacity. This will enable the diffusion effect to be brought into play. Through the support functions of these two regions, it will promote the economic development of the other four regions and gradually narrow the regional differences, so that the economy of the six regions of the province will achieve a balanced development at a high level.

Second, relevant financing agencies can be set up in areas with higher levels of financial aggregation such as the Jinan metropolitan area and the Qingdao metropolitan area. A joint development fund will be set up to use the funds raised for the development of advantageous resources in cities and towns with lower levels of financial agglomeration such as Jizaohe, and to promote economic development in areas with lower levels of financial agglomeration.

Third, on the basis of a thorough understanding of the regional layout of Shandong Province, relevant departments can consider using the advantage of regional financial agglomeration to drive the economic growth of neighboring cities, narrow the financial gap across the region, and promote the rapid development of the overall economy.

\section{REFERENCES}

[1] Zhaoping Tian, "Study on Regional Economic Disparity Evaluation and Coordinated Development in Jiangsu Province," East China Economic Management, 2011, pp.7-12. (In Chinese)

[2] Xia Jiang and Keyan Guo. "Empirical study on the relationship between financial agglomeration and regional economic growth-Based on the analysis of Hubei Province data,” Wuhan Finance, 2016, pp. 11-15. (In Chinese)

[3] Jinhong Wu and Xiujuan Huang, "Study on the Difference of Regional Economic Development in Jiangsu Province,” Journal of Yangzhou University (Humanities and Social Sciences), 2012, pp. 33-39. (In Chinese)

[4] Li Shen and Jianhui Bao, "Research on Regional Disparities in China's Financial Development: An Analysis Based on the Dagum Gini Coefficient Method," Journal of YShandong University of Finance, 2013, pp. 41-48. (In Chinese)

[5] LU Yu and Yuantao Jiang, "Space-time Analysis of Regional Economic Disparity in China: A Comparative Study Based on the National and Three Metropolitan Areas,” Financial and Economic Research, 2007, pp. 17-28. (In Chinese)

[6] Changde Zheng, "Analysis of the Theil index decomposition and its forming factors in the regional differences of China's financial development," Financial and Economic Theory and Practice, 2008, pp. 7-13. (In Chinese)

[7] Chengxue Yu, "A Study on Multiple Indicators of Theil Index in Regional Economic Disparity in China," East China Economic Management, 2009, pp. 40-44. (In Chinese)

[8] Wei Zhao and Ruiyong Ma, "The Difference of China's Regional Financial Growth: Measurement Based on Theil Index,” Economic Geography, 2006, pp. 11-15. (In Chinese) 